\title{
Relevance of Marketing Strategies for Gas Stations in China - An Analysis Using SPSS
}

\author{
Zhe Zhang* \\ University of Baguio, Baguio 2600, Philippines \\ *Corresponding author: Zhe Zhang, 20215996@s.ubaguio.edu
}

\begin{abstract}
This study aims to find out the relevance of marketing strategies for gas stations in China. According to IBISWorld, the companies holding the largest market shares in China's gas station industry include China Petrochemical Corporation, China National Petroleum Corporation, Sinochem Corporation, China National Offshore Oil Corporation, and BP (China) Holdings Limited. Marketing has changed over the past several years. Similarly, gas station marketing is all about more customers, greater sales, and higher profits. Technology provides many different marketing tools to see more fresh faces at the door, increase repeat sales, and improve profits. Word-of-mouth advertising should be encouraged, especially when contests are being held. The prizes from these contests may include car essentials, free coffee, free car wash, or coupons to be used at convenience stores. Customers who have won these contests would surely go around advertising the particular gas station, ultimately bringing in more customers. Other than that, managers can boost the sales volume through radio promotions as well. This study also aims to give future businessmen and women some ideas on how to deal with different kinds of strategies when it comes to marketing, especially in China in hope to cater and prove to the people of China the possibility of promoting businesses, such as the oil industry.
\end{abstract}

Keywords: Marketing strategies; Oil corporation; Gas stations; Oil industry; Advertising

Publication date: December 2021; Online publication: December 31, 2021

\section{Introduction}

Nowadays, in order to maintain the market share in the oil industry, companies need to be more competitive than their competitors in the market. As a result, companies are required to provide more options in their businesses to attract customers into purchasing their main products and other additional services. There are more than 100,000 gas stations across China ${ }^{[1]}$, and car owners have their own ways in dealing with the selection of gas stations. Together, China National Petroleum Corporation (CNPC) and Sinopec account for $46 \%$ of the market share, placing these two leading players in a position of absolute market dominance. According to Deloitte, CNPC and Sinopec own 24,000 (20\%) and 30,600 (26\%) gas stations, respectively [1].

A variety factors such as good services, great environment, or other additional services provided by gas stations lead to different ways in decision-making. Ways on how to promote a certain product, such as petrol, might be easy because it is a commodity. According to Florence School of Regulation, in order to keep the pace of demand, the market structure must further evolve. Its comprehensive reshaping will be driven by new principles: energy policies will enforce new regulation, particularly on midstream business, with the creation of an independent company to manage all infrastructures. On one side, this move aims to foster competition in exploration and production (E\&P) business (by avoiding the captive use of pipelines and allowing a more resolute development of new capacity) in order to increase domestic production and reduce reliance on imports; on the other side, it aims to reduce energy prices for customers by trying to give 
more players the access to downstream markets. It is already happening: a comprehensive "energy law" has already been presented for comments to all stakeholders, and in March this year, NDRC (National Development and Reform Commission), the authority in charge of economic reform, has stated the possibility of moving from regulated city gate gas pricing to market pricing for provinces where there is enough competition on the supply side (typically, coastal region with multiple liquified natural gas [LNG] plants). Companies like Beijing Gas, ENN, and China Resources Gas that are managing retail businesses in big cities (Beijing, Shanghai, and Shenzhen) are posing new challenges to the three giants. They have built their own LNG terminals as they wish to have independent supplies, in order to escape the current constraints on regulated wholesale gas pipeline price, and to enjoy TPA on transportation and regasification capacity. The retail market is consolidating (with big utilities and the three giants acquiring smaller players) and experiencing more competition (even if in most of the cities there is only one provider). Gasoline and other petroleum refinery products are important not only to consumers' budgets but to the functioning of the economy as a whole. The increase in road fuel prices affect not only motorists but also the prices of many other goods due to the rise in transport costs. During periods of high gasoline prices, heightened public attention is drawn into the functioning of fuel markets with concerns of possible anticompetitive practices.

As illustrated in Figure 1, CNPC's marketing system is three-tiered. The first tier is the China Oil Distribution Corp., a 100\% subsidiary of PetroChina. It is responsible for drawing up CNPC's oil production and sales plans, selling products nationwide through its regional marketing units, and developing medium- and long-term marketing strategies. The second tier consists of four regional distributors: East China Distribution Corp., North China Distribution Corp., Southwest China Distribution Corp., as well as provincial and municipal distribution corporations. They are engaged in wholesale and delivery services largely in the provinces to which they belong. The third tier comprises of provincial enterprises controlled by the aforesaid regional distributors. They are in charge of wholesale, retail, and delivery services within their service areas. The fourth tier consists of county/district distributors belonging to related provincial enterprises. Their primary assignments are SS (service station) management and marketing or delivery services to general users, as well as affiliated or non-affiliated SSs.

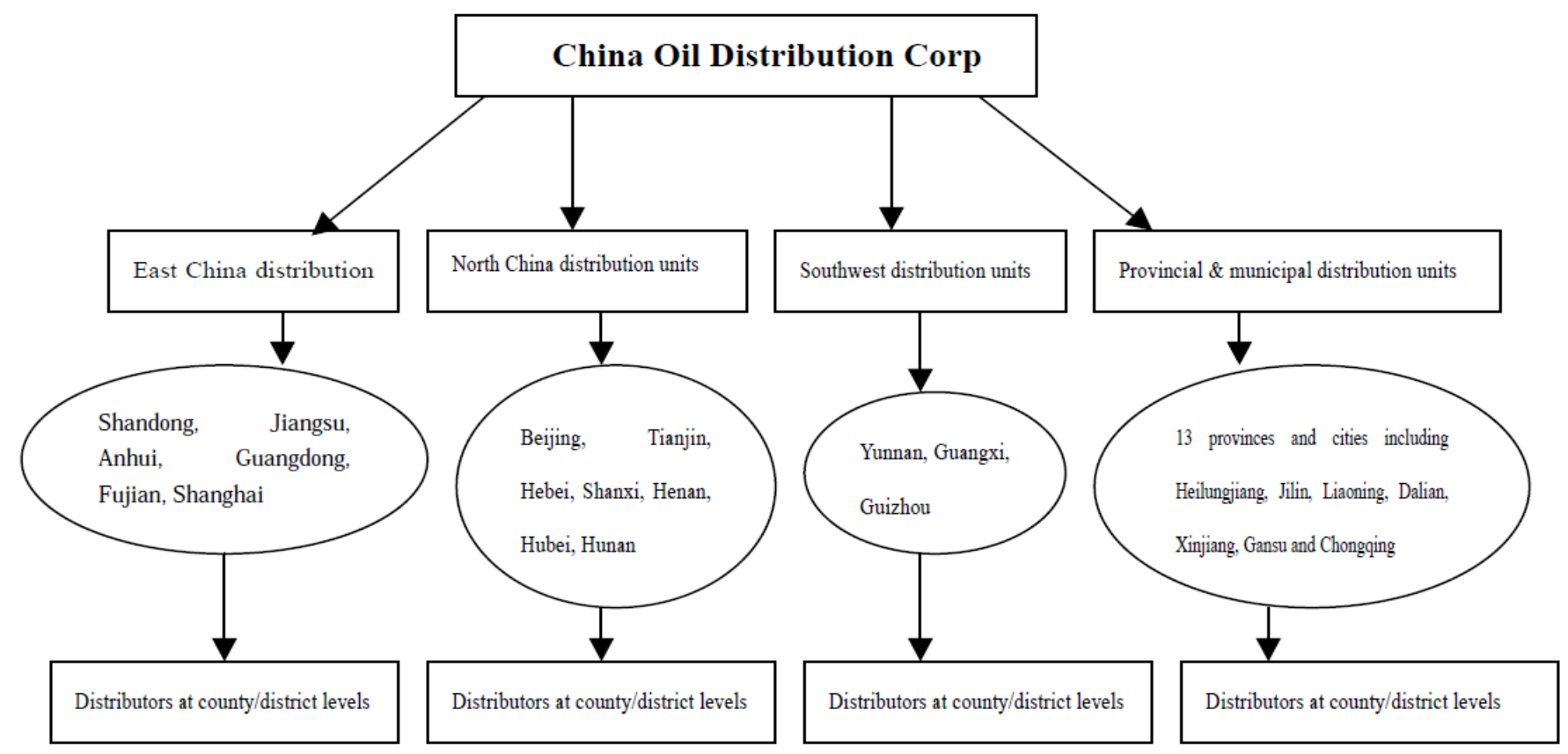

Figure 1. Oil Marketing System of CNPC [1] 
China has been very consistent when it comes to large petroleum products importation. The main problem in this is the conflicts within a certain business using ineffective marketing strategies. While its economic dynamism stimulates continuous growth in Asia, China's increasing demand for energy is creating intense competition, particularly with Japan, over international sources of supply ${ }^{[2]}$. Domestic fields have generally been disappointing, as have efforts to pipe gas from Central Asia and Russia to the east coast. Consequently, China is not only paying greater attention to potential petroleum resources in the East and South China Sea but also considering the vulnerability of its sea-lanes to the Middle East and beyond. Its need to diversify has promoted closer relations with Central Asia, the Middle East, and oil producing countries in Africa and Latin America, but the jury is out on whether China's concerns for secure energy supply would lead to international cooperation against terrorism or fuel the already heated competition for oil and gas. As China continues to assure its future energy security in Asia and many regions around the world, sustained bilateral and multilateral diplomacies to reconcile disputes and avoid conflicts would be far more important than ever.

This study is conducted with the aim of developing a new marketing strategy that will benefit oil businesses in China and relate the relevance of marketing strategies among gas stations in China to the new era. This study would help in understanding the current market of gas stations in China by developing a marketing strategy for gas stations, improving the competitive advantage for gas stations, and sustaining business growth of gas stations while maintaining the leader position in the market. The objectives of this study are to be met through a quantitative study by conducting a survey and gathering secondary data which would be analyzed using SPSS.

\section{Methodology}

This independent study is a quantitative research. In this study, data have been collected via questionnaire about customers' expectations toward a gas station and the factors that influence their decisions in choosing a certain gas station. The questionnaire consists of two parts. The first part is a survey of the importance of the 7Ps of service marketing that affect the decision-making process in choosing PTT gas station. In this part, customers are required to evaluate the levels of importance of variable factors that influence them in choosing PTT gas station. The factors include product, price, place, promotion, people, physical evidence, and process. The questions are rated by using a Five-Point Likert scale as an interval scale as shown in Table 1. The second part consists of a checklist to obtain the respondents' general information, including gender, age, occupation, income, and type of customers.

Table 1. Criteria for the scale of importance in the questionnaire

\begin{tabular}{cc}
\hline Level of importance & Weight (points) \\
\hline Very important & 5 \\
Important & 4 \\
Moderately important & 3 \\
Of little importance & 2 \\
Unimportant & 1 \\
\hline
\end{tabular}

In regard to the criteria for evaluation, class interval is used. The highest point is 5 and the lowest is 1 . The calculation of class interval is by subtracting the lowest value from the highest value in the data set and dividing by the number of classes. The formula is as follows: 
Class interval $=$ Highest value - Lowest value $/$ Number of classes

$=5-1 / 5$

$=0.8$

Hence, the interpretation of the average points at each level of importance is as shown in Table 2.

Table 2. Interpretation of the average points at each level of importance

\begin{tabular}{cc}
\hline Average point & Level of importance \\
\hline $4.21-5.00$ & Very Important \\
$3.41-4.20$ & Important \\
$2.61-3.40$ & Moderately Important \\
$1.81-2.60$ & Of Little Importance \\
$1.00-1.80$ & Unimportant \\
\hline
\end{tabular}

In order to reach the target group, the survey was carried out at every gas station in China, specifically in metro cities, where the questionnaires were distributed to the customers. Two data sources were used in this study: primary data and secondary data. This study mainly relied on primary data, which were collected from the customers at Sinopec Beijing, PetroChina Shanghai, Shell Guangzhou, and Chengdu Jiaotou Filling Station through the questionnaire. In order to design the questionnaire, the secondary data were collected from the internet through various sources, authors, articles, analysts, and researchers related to the objectives of this study.

\section{Results and discussion}

\subsection{Management of gas stations}

In the Chinese filling station market, state-claimed undertakings, private firms, and unfamiliar organizations exist together, among which state-possessed endeavors have been addressed by CNPC, Sinopec, and CNOOC (China National Offshore Oil Corporation), which shared a piece of the pie of roughly $52 \%$ in 2018 , trailed by private firms with $45 \%$, and unfamiliar organizations with $3 \%$ [3].

In June 2018, the Special Administrative Measures (Negative List) for Foreign Investment Access (2018) was announced, which authoritatively nullified the limitation that unfamiliar organizations possessing more than 30 chains ought to have their shares constrained. As a result, unfamiliar organizations like Shell and BP expressed their extension plans in China for what is to come. Shell is quick to work 2,200 additional filling stations in China by 2025; BP wishes to develop 1,000 filling stations in China over the course of the following five years; Exxon Mobil and Total are sticking to this same pattern and making their introductions to the Chinese retailing market quickly. Furthermore, private firms, such as Shandong Dongming Petrochemical Group, alike state-possessed endeavors, such as Sinochem Oil, have communicated an interest in either expanding an extraordinary number of filling stations or creating diversified ones. It would be expected that in 2025, there will be an absolute increment of almost 30,000 filling stations over the figure in 2018.

\subsection{Market strategies of gas stations}

These days, corner stores turn out to be more alike help station centers, selling oil-based goods. The pattern later on will turn out to be more centered on non-oil administrations ${ }^{[4]}$. Non-oil businesses in service stations turn out to be more effective and produce more income. Non-oil businesses are making an 
appearance through shop rental, joining with potential retail administrators or structuring their own image for retail items to be included in these stations. With rapidly changing interest and the conduct of customers, customers do not only make trips to top off their gases, but they additionally need different services provided by these stations, some for rest and some to shop. The top management in this industry ought to modify these stations expeditiously. The oil industry assumes an imperative role in the establishment of the public economy in China. In spite of the way that few changes have been executed effectively in the previous years, there are still some persistent issues. Besides, with the new-typical economy, the progress to environmentally friendly power energy and worldwide exchange debates, new difficulties and issues are arising. This review presents the current difficulties and relating measures through a survey of the chronicled improvement of China's oil industry.

The authentic outline of China's oil market is led from the organization, market structures, oil imports, and evaluating systems. Five issues have been summed up: the absence of marketization, abundance oil refining limit, high outside reliance, climate contamination, and temperamental global exchange relationships. In order to address the issues, several countermeasures have been proposed. First, it is essential to advance market change; build up a more straightforward market-based evaluating framework by setting clear principles and conditions or embracing formula-based estimating techniques. Second, the Chinese government should encourage the consolidation of small and medium-sized treatment facilities and the development of incorporated refining and substance undertakings as well as consequently speed up the stage out of old refining limit. Third, the expansion of oil supply sources can be contributed by expanding homegrown creation, improving the wellspring of oil imports, upgrading abroad speculation, and setting up essential oil saves. To wrap things up, the enemy of homegrown petrol ventures - hazard capacity ought to be worked on in light of unpredictable oil costs brought by global exchange questions.

\subsection{Ps of marketing}

The advertising of items is identified with unmistakable merchandise; it is easy to characterize item showcasing by the 4Ps of showcasing: product, price, place, and promotion ${ }^{[5]}$. The mission of product advertising is to showcase a certain product to the current clients and scout for prospect clients. In the service industry, substantial merchandise and elusive products are joined together. This way of advertising is unique. The first four components are somewhat very similar but adding 3Ps - people, process, and physical evidence serves the business better. In this investigation of service stations, the 7Ps of marketing are alluded to concentrate on the conduct of clients and on fostering the methodology of showcasing to maintain business development.

(1) Product is labor, and products provided by the stations serve the clients. The main product in service stations is fuel, in which the quality of the product is incorporated. Each brand needs to ensure that their products serve their clients in such way that they would appreciate both the brand and quality. Since the public authority oversees oil-based goods, gas stations are homogeneous. The clients have various options for substitution. The fundamental marketing strategy for service stations are the different administrations in non-oil businesses. Non-oil businesses are advantageous to these stations; they are situated in these stations to serve the needs of the customers. The administrations of these stations need to cooperate with major retails to draw in clients, in order to secure more income.

(2) Price is a measure of cash paid to obtain certain items or administrations. In service stations, the cost of the item is not distinctive in view of unofficial laws. The Energy Policy and Planning Office would control the value of oil-based goods. Therefore, it is difficult to utilize the value technique in gas stations. 
(3) Place is the circulation channel of items and administrations. For gas stations, it implies the measure of corner stores accommodating the clients. In China, there are five major corner stores serving the country. China Petroleum and Chemical Corp., referred to casually as Sinopec, is an oil, gas, and synthetic goliath and is likewise one of the world's greatest organizations. The organization is positioned as the second right on the money in Fortune Global 500 among worldwide organizations, with revenue of more than $\$ 414$ billion in 2019 , being more prominent than other oil organizations on the planet. While homegrown oil creation adds up to an excess of 300 million barrels, creation from oil fields abroad is around 50 million barrels. Sinopec takes the best position in this rundown based on its combined income, yet it is China's second-greatest raw petroleum maker by volume. China National Petroleum Corporation, or CNPC, is the second-biggest Chinese raw petroleum maker by combined income and the greatest by creation volume. The organization is positioned as the fourth right on the money in Fortune Global 500, with more than $\$ 392$ billion in combined income. China National Offshore Oil Corporation, known as CNOOC, centers around oil and gas investigation and creation in China's seaward waters. It has become a worldwide organization with activities in excess of 40 nations. CNOOC procured more than $\$ 108$ billion in combined income, positioning at the 63rd place among Fortune's top worldwide organizations in 2019. Shaanxi Yanchang Petroleum follows its set of experiences back to the Yanchang Oil Plant - the main oil endeavor set up in China. The organization takes part in oil and gas investigation and creation as well as refining tasks in areas all around the world. The majority of its tasks are coordinated under its auxiliary, Yanchang Petroleum International, which is recorded on the HKG. Sinochem Group was set up during the revamping of China's biggest global trading firm, China National Chemicals Import and Export Corporation. Sinochem Group stays one of the biggest substance organizations in the nation; however, it has extended its activities to incorporate energy, land, horticulture, and monetary administrations. The organization procured more than $\$ 89$ billion in income, taking the 88th spot on the Fortune Global 500 rundown in 2019.

(4) Promotion is the pursuit proposed to customers while selecting a corner store. It comprises of activities or occasions that associate the buyers to the brand. It entails the correspondence between dealers and purchasers. It additionally expands the commitment of clients and stimulates a positive attitude toward a certain brand. There are numerous methods of promotion, such as publicizing and promotional deals. These days, web-based media is one of the channels to promote brands and speak with the clients via Facebook, Instagram, Line, and so forth. It is exceptionally significant and has affected the clients' dynamic.

(5) People, in this context, refer to the staffs who convey the items and interact with clients. For corner stores, service station chaperons are the people who intrigue the clients in seeking the service from help stations. Therefore, corner store chaperons and the staffs working at the station need to work well. As a result, customer care has become a main concern for several associations today.

(6) Process is the standard that is conveyed to the clients. Standard is extremely critical for interaction since it guarantees that a similar method of administration is more than once served to the clients. A flawless standard conveyed to the clients could prompt great impression among those who utilize the administration. Therefore, the majority of administrations have manuals or standard methods to follow, such as using specific words in greetings and so on.

(7) Physical evidence refers to the actual things that can be seen by the clients, which influence their experience, such as the climate around the station, temperament and tone of the station, as well as the indication of the brand. Therefore, a good environment and other physical matters around the station may have an effect on the clients' experience. 


\subsection{Relationship between the 7Ps and demographic factors}

The purpose of this study is to determine the factors that influence the choice of gas stations in four metro cities in China based on the 7Ps of marketing (product, price, place, promotion, people, physical evidence, and process) and the demographic factors, including gender, age, occupation, and income. In this section, SPSS was used to evaluate the raw data. Thereafter, the concluded results were presented in the table form and descriptively. In summary, the factors that have relationship with every demographic factor include product, price, place, promotion, and physical evidence (5Ps of service marketing mix).

The first is product mix. The sub-factor of product mix that has relationship with every demographic factor (gender, age, occupation, and income) is the provision of other alternative energy products by the gas station, such as LPG and NGV (natural gas vehicle). Another sub-factor is that the gas station offers other services, such as car cleaning services, engine oil change services, etc. The next is price mix. The sub-factor of price mix is related to every demographic factor, which is cheaper price for both oil and other services compared with other competitors. Place mix also has relationship with every demographic factor. The sub-factor is the provision of a sign indicating the distance before reaching the gas station. Promotion mix has many sub-factors that have relationship with the demographic factors. The sub-factors of promotion include drinking water giveaways and discount vouchers for use with other services, such as car cleaning services, engine oil change services, and shopping. Another sub-factor is sweepstakes campaigns, with prizes such as gold, cars, etc. Moreover, projects that will create shared value (CSV) through the community is another sub-factor. In regard to physical evidence mix, the sub-factor that has relationship with every demographic is clean and adequate toilets provided by the gas station.

\section{Conclusion}

This independent study on the relevance of marketing strategies for gas stations aims to explore the behavior of customers in the selection of gas stations in four metro cities in China and establish a service marketing strategy for gas stations to ultimately drive sustainable, long-term growth as well as profitability.

Additionally, using cross tab analysis, it has illustrated that the factors of service marketing that have relationship with every demographic factor are product, price, place, promotion, and physical evidence. Overall, the level of importance of sub-factors in influencing the selection of gas stations falls in the categories of very important and important except for the sub-factors of product, whereby having local guide (tourist information) and hotel services in gas stations are of moderate importance.

\section{Recommendations}

From the survey, the percentage of both local users and travelers are quite close. There are several suggestions in using the 7Ps of service marketing.

(1) In terms of product, gas stations should maintain a strong brand, which is accepted and reliable, taking into consideration of the customers. Moreover, additional services are crucial. ATMs are examples of additional services that influence the customers' choice in selecting a particular gas station. On the other hand, additional products are also important; gas stations should offer other products commonly seen in convenience stores, kiosk, souvenir shops, co-brands, and OTOP (One Tambon One Product) stores to meet the customers' needs. However, from the survey, there were complains about the quality of certain products; hence, gas stations should ensure the quality of their products and advertise more so that customers would realize the improvement in quality.

(2) In terms of price, although the government governs the price structure of oil, knowing that, customers are still particular about prices. Therefore, the owners of gas stations should be more 
involved in informing customers and updating the prices through their Facebook pages as a way of communicating with their customers. This allows local users to interact with these stations through media, and not only physically at those stations.

(3) In terms of place, a strong location point is still significant. In order to serve both travelers and local users, gas stations should be developed in the community and in areas that are easy to find.

(4) In terms of promotion, gas stations should inform their customers about the offered promotions, such as points collection for card members or sales promotions using credit cards, to ensure that the customers are involved in all available promotions. Furthermore, it is important to support projects for the community to participate in, thus creating shared value (CSV), so that local users would be able to share the success and feel as though they are a part of the station.

(5) In terms of people, the owners of gas stations should train their employees to cultivate a service mindset in order to maintain a certain standard quality in their service. This would create a strong advantage for the station.

(6) In terms of physical evidence, the owners of gas stations should provide one-stop-services for their customers. These services very significant for the customers. Other than that, gas stations should be spacious, with adequate parking lots and easy access - exit. On the other hand, one of the recommendations that affects customers' satisfaction is green space.

(7) In terms of process, gas stations should support various payment methods, especially in consideration of the cashless society nowadays, where people tend pay with all sorts of methods other than by cash. More importantly, gas stations should deliver fast and convenient services.

\section{Disclosure statement}

The author declares that there is no conflict of interest.

\section{References}

[1] Zhi GS, 2003, Trends of Petroleum Distribution Business in China. IEEJ. https://eneken.ieej.or.jp/data/en/data/pdf/195.pdf (accessed on October 28, 2021).

[2] Kenny HJ, 2004, China and the Competition for Oil and Gas in Asia. Asia Pacific Review, 11(2): 3647. DOI: $10.1080 / 1343900042000292533$

[3] Research and Markets, 2019, China Filling Station and Gas Station Industry Report, 2018-2025. Cision PR Newswire. https://www.prnewswire.com/news-releases/china-filling-station-and-gas-stationindustry-report-with-forecasts-to-2025-300846307.html (accessed on October 29, 2021).

[4] Chen S-Y, Zhang Q, Mclellan B, et al., 2020, Review on the Petroleum Market in China: History, Challenges and Prospects. Petroleum Science, 17: 1779-1794. https://link.springer.com/article/1 0.1007/s12182-020-00501-6

[5] Kongmee T, 2018, Service Marketing Strategy for PTT Gas Stations. Thammasat University. http://ethesisarchive.library.tu.ac.th/thesis/2018/TU_2018_6002043112_9819_10290.pdf (accessed on October 31, 2021). 